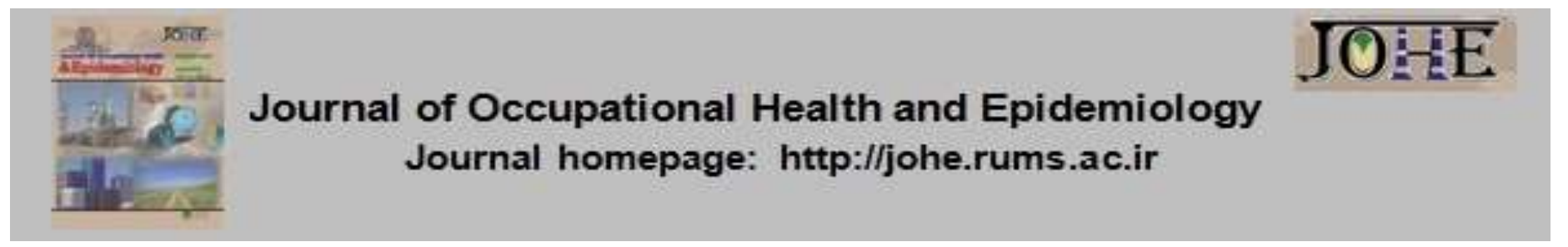

\title{
Lifetime prevalence of cutaneous leishmaniasis scar in the city of Kherameh, Fars province, Iran (2015)
}

\author{
Hojjatollah Khosravani Poor ${ }^{1^{*}}$, Mohsen Ali Akbar Poor ${ }^{2}$, Ali Zare Askari ${ }^{3}$, Mostafa Danesh ${ }^{4}$, Abozar \\ Keshavarz ${ }^{5}$, Behnaz Palizian ${ }^{6}$
}

1. PhD Student in Healthcare Management, Islamic Azad Semnan University, Semnan, Iran.

2. MSc in Epidemiology, Shiraz University of Medical Science, Shiraz, Iran.

3. PhD Student in Healthcare Management, Islamic Azad Semnan University, Semnan, Iran.

4. MSc in Power Man Management, Shiraz University, Shiraz, Iran.

5. MSc in Health Promotion and Education, Shiraz University of Medical Science, Shiraz, Iran.

6. DDs in Dental, Shiraz University of Medical Science, Shiraz, Iran.

\section{Citation: Khosravani Poor H, Akbar Poor MA, Zare Askari A, Danesh M, Keshavarz A,
Palizian B. Lifetime prevalence of cutaneous leishmaniasis scar in the city of Kherameh, Fars
province, Iran (2015). JOHE. 2019; 8(1):12-20.}

\section{Article Info}

* Corresponding author: Hojjatollah Khosravani Poor E-mail:

dehkadehjahani00a@gmail. com

\section{Article history}

Received: Oct, 2018

Accepted: Feb, 2019

10.29252/johe.8.1.12

Print ISSN: $2251-8096$ Online ISSN: 2252-0902

Peer review under responsibility of Journal of Occupational Health and Epidemiology

\begin{abstract}
Background: Second only to malaria, cutaneous leishmaniasis is considered the most serious disease in tropical and subtropical areas around the world. Although leishmaniasis is a self-limited disease, the scar left by it on the affected person's skin can cause mental and emotional problems. The present study investigated the lifetime prevalence of cutaneous leishmaniasis scar among the affected people in the city of Kherameh in 2015. Materials and Methods: Using a census method in this cross-sectional study, we interviewed 11905 families in the city of Kherameh. The epidemiological data were collected using a researcher-made questionnaire prepared through scientific methods and were analyzed through Pearson, t-test, Fisher's, and Chi-square tests.

Results: The cutaneous leishmaniasis prevalence was estimated to be $31.49 \%$ across the studied area, with the scar lifetime prevalence of $25.93 \%$ and $20.32 \%$ among the female and male participants, respectively. The highest age-gender specific prevalence was found among the 5-9 years old female participants. Furthermore, the risk of the disease recurrence was found to be $0.68 \%$.

Conclusion: There was a high rate of the cutaneous leishmaniasis prevalence in the region under study and it was found that the disease do not provide lifelong immunity. To control the disease, it is necessary to find more effective solutions and take appropriate controlling actions.
\end{abstract}

Keywords: Cutaneous Leishmaniasis, Prevalence, Sand Fly, Scar, Iran.

\section{Introduction}

Despite the significance advances made in controlling diseases during the recent years, Leishmaniasis is still regarded as one of the six most serious diseases affecting inhabitants in tropical and subtropical areas in the world $(1,2)$. However, it is generally forgotten due to the lack of effective, economical, and available medicines $(3,4)$. Leishmaniasis is a parasitic disease caused by a unicellular organism named Leishmania and it is conveyed to human by the bite of Phlebotomus fly
(5), and is clinically classified as a cutaneous, mucocutaneous, diffuse cutaneous, and visceral disease (6).

Among its clinical forms, cutaneous leishmaniasis is the most frequent type, and about 350 million people are at risk of developing it. The global prevalence of the disease is 12 million people and its annual incidence is about 1.5 to 2 million people (7-9). Cutaneous leishmaniasis is endemic in 88 countries of the world including Afghanistan, Algeria, Colombia, Brazil, Iran, Syria, Ethiopia, 
North Sudan, Costa Rica, and Peru with the highest prevalence rate in the world (10-12).

Along with the increased deforestation, urbanization, population dynamicity, and climate change in many areas of the world, leishmaniasis has turned into a major challenge for public health (13). Every year, about 15 thousand people develop leishmaniasis in Iran and according to the available studies, the actual rate is 4 to 5 times greater than what is reported (14). Although leishmaniasis rarely leads to death, three main reasons can make it hard for the patients to bear the disease, especially its complications: First, it threatens the patients' appearance and beauty. Second, the disease takes long to be treated. And finally, some lesions and scars will be left on the patient's skin. Based on the type of leishmaniasis, the time to recover from the disease lasts 2 to 6 months in the rural type, while it lasts 6 to 15 months in the urban type (15-17).

The sources of the urban type of the disease are humans and dogs, and the source of the rural type is rats $(15,18)$. The rural type is considered a serious health problem in the countries of the Eastern Mediterranean area including Iran (19). Fars Province is one of the most critical areas prone to leishmaniasis in Iran, and leishmaniasis cases are increasing in some parts of the province including the city of Kherameh, Shiraz $(20,21)$.

The degree of the leishmaniasis prevalence is affected by economic, social, cultural, environmental, and ecologic factors (22). Given the varieties and biological conditions of the disease, it is not practical to select a single method to control leishmaniasis (23). One of the important strategies for controlling leishmaniasis is the use of personal protective equipment (24). Studies have shown that using insecticide-treated mosquito nets can protect people in $50 \%$ to $60 \%$ of the cases against infections or leishmaniasis (25).

According to different reports, the prevalence of cutaneous leishmaniasis has been $1.8 \%$ to $37.9 \%$ in different provinces of Iran (26). Several studies have been conducted on the prevalence of cutaneous leishmaniasis in different parts of the world including: Inci et al in Turkey (27), Khan et al in Surgul village in India (28), Eilami and Khalili in Yasuj (29), and Aflatunian et al in Bam (30).

These studies have estimated point prevalence in short-term periods in the affected areas. Besides, to the best of our knowledge, there is no comprehensive study on the prevalence of leishmaniasis scar. Given this gap in the literature, the present study aimed at investigating the prevalence of cutaneous leishmaniasis scars among the families in the city of Kherameh in 2015.

\section{Materials and Methods}

The present study is a cross-sectional research conducted in 2015. The epidemiological data were collected using a researcher-made questionnaire prepared through scientific methods. The questionnaire items were about year of the development of leishmaniasis lesions and the type of lesions (active or passive), secretion or nonsecretion, and finally the use of bed nets. The research population included all families (12384 in total) living in Kherameh, Fars province who completed the questionnaires through the census method including interviews and examinations. The families reluctant to participate in the study were excluded. In this study, experienced individuals (health workers who were familiar with leishmaniasis lesions and scars for many years) were employed as interviewers. The interviewers personally referred to the participating families and interviewed the family members to find out if they had developed active wounds and scars. The questionnaires were completed based on the respondents' answers to the interviews. The collected data were analyzed using Pearson correlation test, t-test, Fischer test, and chi-square test in SPSS software (version 16) and EXCEL (version 2007). The research hypotheses were tested at significant level of 0.05 .

\section{Results}

There were 12384 families in the city of Kherameh at the time of conducting the study. However, 479 families were excluded from the study: 69 families had migrated to the region under study and 410 families either avoided participating in the study or were not present when the researchers referred to them to complete the questionnaires.

The participants were 11905 family mothers. The mean and standard deviation of the mothers' age was $42.47 \pm 14.694$. The mean and standard deviation for the family size was $3.65 \pm 1.878$ people. The results of the study indicated that the participating mother had different education levels: primary education in 3145 families (26.3\%), middle school education in 2179 families (18.2\%), high school diploma in 2109 families (17.6\%), associate degree and higher in 900 families (7.5\%), and 3572 uneducated families $(29.8 \%)$. besides, most participants were housewives $(11214.51$ families $=$ $94.2 \%$ ). In addition, most families (6941 families = $58 \%$ ) had an income lower than 5 million Rials per month (table 1). 
Table 1: Demographic characteristics of the participants

\begin{tabular}{|c|c|c|}
\hline Variable & Subgroup & Frequency (\%) \\
\hline \multirow{7}{*}{ Age (year) } & Below 24 years & $922(7.7)$ \\
\hline & $25-34$ & $3346(27.9)$ \\
\hline & $35-44$ & $2887(24.1)$ \\
\hline & $45-54$ & $2155(18.0)$ \\
\hline & $55-64$ & $1503(12.6)$ \\
\hline & $65-74$ & $771(6.4)$ \\
\hline & 75 and higher & $391(3.3)$ \\
\hline \multirow{5}{*}{ Occupation } & Housewife & $11281(94.2)$ \\
\hline & Employee & $430(3.6)$ \\
\hline & Worker & $38(0.3)$ \\
\hline & Retired & $47(0.4)$ \\
\hline & Others & $111(0.9)$ \\
\hline \multirow{3}{*}{ Number of family members } & $1-3$ & $5557(46.4)$ \\
\hline & $4-5$ & $5417(45.2)$ \\
\hline & Higher than 5 & $931(8.4)$ \\
\hline \multirow{3}{*}{ Family income (Rial) } & $>5000000$ & $6941(58)$ \\
\hline & $5000000-15000000$ & $4256(35.5)$ \\
\hline & $<15000000$ & 707 (5.9) \\
\hline
\end{tabular}

In the study, 43467 people in the region under study were examined for scars and active lesions. Since few cases had been found from 1970 to 1980,1981 was considered the starting point of investigation. From the early of 1981 until 2015, a total number of 10787 patients with cutaneous leishmaniasis were identified in 25 districts through the city. In the 34year period under study, the minimum number of cutaneous leishmaniasis cases was found during 1981-1990 and the maximum number of cases was identified during 2013-2015 (Figure 1).

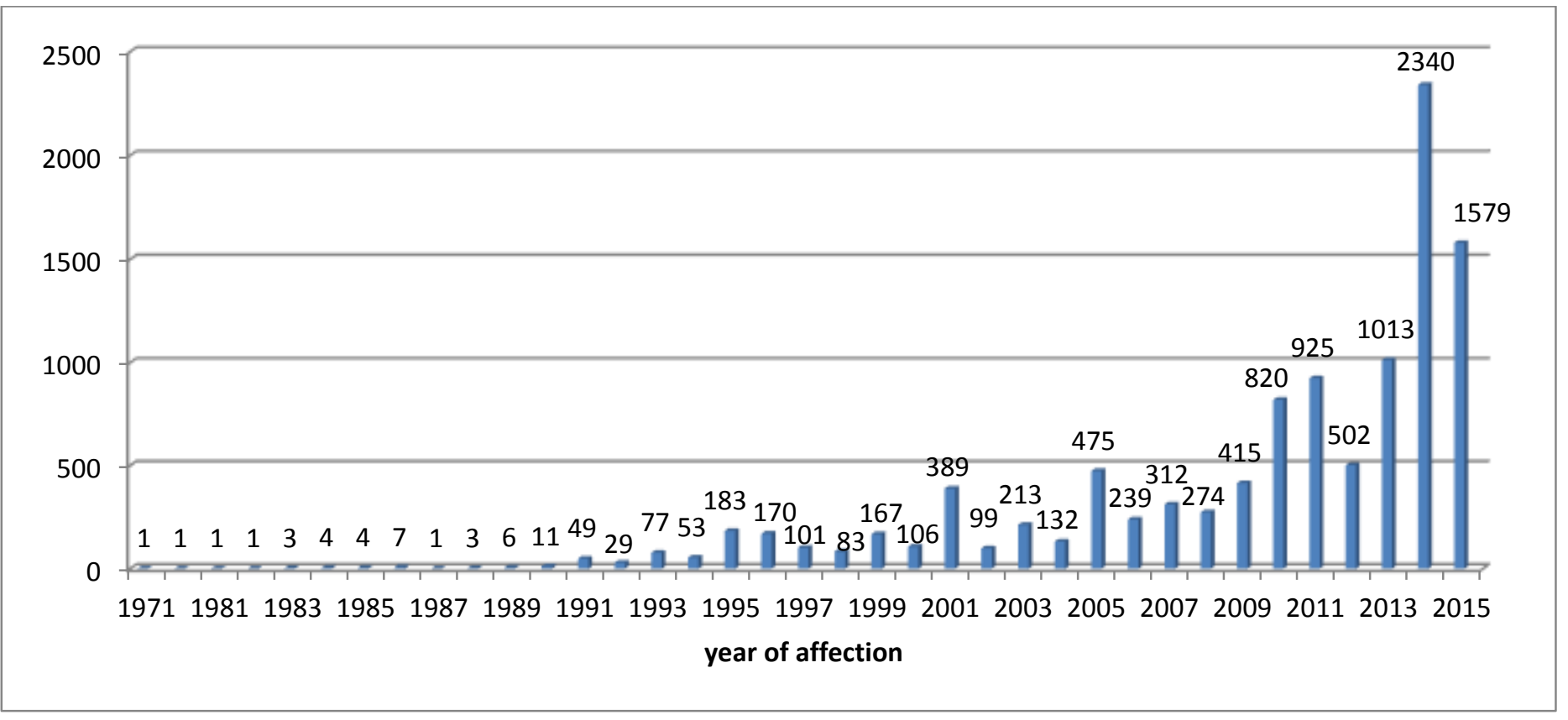

Figure1: Cutaneous leishmaniasis frequency based on year of affection

The besides, the prevalence of cutaneous leishmaniasis in the region under study was $31.49 \%$. The lowest prevalence was found in Eslam Abad region and the highest was in Salamat Abad (Table 2). The lifetime prevalence of scars was estimated to be $25.93 \%$ among the females and $20.32 \%$ among the males. The highest prevalence of the disease was found in the age group below 10 years old. The age group 5-9 years old showed the highest age-gender specific prevalence rate. As the present study was a cross-sectional investigation, the prevalence of the scars was estimated for each age group through a cross-sectional perspective (Table 3). 
Table 2: Prevalence of cutaneous leishmaniasis in different regions in the city of Kherameh

\begin{tabular}{|c|c|c|c|}
\hline \multirow{2}{*}{ Region } & \multicolumn{2}{|c|}{ Frequency of $\mathrm{CL}$} & \multirow{2}{*}{ Prevalence } \\
\hline & Female (\%) & Male (\%) & \\
\hline Abshoor & $280(18)$ & $261(16.78)$ & $541(34.79)$ \\
\hline Ahmad Abad & $55(11.85)$ & $45(9.69)$ & $100(21.98)$ \\
\hline Bonjeer & $107(14.59)$ & $102(13.91)$ & $209(35.89)$ \\
\hline Eslam Abad & $15(1.59)$ & $12(1.27)$ & $27(2.97)$ \\
\hline Esmaeel Abad & $37(18.5)$ & $27(13.5)$ & $64(31.5)$ \\
\hline Ghavam Abad & $230(22.59)$ & $180(17.60)$ & $410(39.98)$ \\
\hline Gheshlag - Darniyan & $112(27.86)$ & $84(20.89)$ & $196(48.75)$ \\
\hline Helal Abad & $74(17.09)$ & $65(15.01)$ & 139(32.10) \\
\hline Hossein Abad & $102(21.16)$ & $72(14.93)$ & 174(35.89) \\
\hline Kafdahak & $241(14.96)$ & $226(14.03)$ & $467(28.50)$ \\
\hline Kamjan & $244(14.61)$ & $203(12.16)$ & $447(26.24)$ \\
\hline Kharestan & 157(18.69) & 122(14.52) & $279(33.21)$ \\
\hline Kheir Abad & $662(17.59)$ & $519(13.79)$ & $1181(31.36)$ \\
\hline Kooh Kheiareh & $258(11.47)$ & $232(10.31)$ & $490(21.74)$ \\
\hline Mehr Abad & $51(5.92)$ & $32(3.71)$ & $83(9.63)$ \\
\hline Moez Abad & 736(11.70) & $598(9.50)$ & 1334(21.12) \\
\hline Moez Abad-e-Goorgeer & $77(18.96)$ & $75(18.47)$ & 152(37.43) \\
\hline Noor Abad & 124(27.61) & $84(18.70)$ & $208(46.32)$ \\
\hline Roobahghan & $153(26.37)$ & $105(18.10)$ & $258(44.48)$ \\
\hline Salamat Abad & $80(24.02)$ & $80(24.02)$ & $160(48.94)$ \\
\hline Sejel Abad & $417(17.96)$ & $288(12.40)$ & $705(30.11)$ \\
\hline Kherameh City & $945(8.14)$ & $864(7.44)$ & 1809(15.66) \\
\hline Shahrak-e-Isar & $314(15.92)$ & $246(12.42)$ & $560(28.39)$ \\
\hline Sofla & $142(18.20)$ & $144(18.46)$ & $286(36.92)$ \\
\hline Soltan Abad & $284(18.82)$ & $223(14.77)$ & $507(30.28)$ \\
\hline Total & $5897(54.67)$ & $4889(45.33)$ & $10786(100)$ \\
\hline
\end{tabular}

Table 3: Prevalence of Cutaneous Leishmaniasis based on age and gender

\begin{tabular}{|c|c|c|c|c|c|c|c|}
\hline \multicolumn{2}{|c|}{ categories } & \multirow{2}{*}{ Active lesion } & \multirow{2}{*}{ Scar } & \multirow{2}{*}{ Total } & \multirow{2}{*}{ Total \% } & \multirow{2}{*}{ Population } & \multirow{2}{*}{$\begin{array}{c}\text { Age-gender } \\
\text { specific prevalence }\end{array}$} \\
\hline Age (year) & Gender & & & & & & \\
\hline \multirow{2}{*}{$0-4$} & Female & 191 & 621 & 812 & \multirow{2}{*}{$\begin{array}{c}1616 \\
(34.35) \\
\end{array}$} & 2253 & 36.04 \\
\hline & Male & 155 & 649 & 804 & & 2451 & 32.80 \\
\hline \multirow{2}{*}{$5-9$} & Female & 114 & 604 & 718 & \multirow{2}{*}{$\begin{array}{c}1417 \\
(34.63) \\
\end{array}$} & 1991 & 36.06 \\
\hline & Male & 100 & 599 & 699 & & 2100 & 33.28 \\
\hline \multirow{2}{*}{$10-14$} & Female & 56 & 501 & 557 & \multirow{2}{*}{$\begin{array}{c}1125 \\
(35.20) \\
\end{array}$} & 1592 & 34.98 \\
\hline & Male & 62 & 506 & 568 & & 1604 & 35.41 \\
\hline \multirow{2}{*}{$15-19$} & Female & 36 & 388 & 424 & \multirow{2}{*}{$\begin{array}{c}851 \\
(31.67)\end{array}$} & 1276 & 33.22 \\
\hline & Male & 40 & 387 & 427 & & 1411 & 30.26 \\
\hline \multirow{2}{*}{$20-24$} & Female & 51 & 407 & 458 & \multirow{2}{*}{$\begin{array}{c}933 \\
(23.92)\end{array}$} & 1812 & 25.27 \\
\hline & Male & 47 & 428 & 475 & & 2088 & 22.74 \\
\hline \multirow{2}{*}{$25-29$} & Female & 76 & 385 & 461 & \multirow{2}{*}{$\begin{array}{c}790 \\
(14.44) \\
\end{array}$} & 2531 & 18.21 \\
\hline & Male & 47 & 282 & 329 & & 2939 & 11.19 \\
\hline \multirow{2}{*}{$30-34$} & Female & 69 & 374 & 443 & \multirow{2}{*}{$\begin{array}{c}759 \\
(14.71)\end{array}$} & 2456 & 18.03 \\
\hline & Male & 48 & 268 & 316 & & 2701 & 15.25 \\
\hline \multirow{2}{*}{$35-39$} & Female & 43 & 331 & 374 & \multirow{2}{*}{$\begin{array}{c}623 \\
(15.02)\end{array}$} & 2003 & 18.67 \\
\hline & Male & 28 & 221 & 249 & & 2143 & 11.61 \\
\hline \multirow{2}{*}{$40-44$} & Female & 58 & 295 & 353 & \multirow{2}{*}{$\begin{array}{c}550 \\
(17.39)\end{array}$} & 1487 & 23.73 \\
\hline & Male & 27 & 170 & 197 & & 1674 & 11.76 \\
\hline \multirow{2}{*}{$45-49$} & Female & 50 & 252 & 302 & \multirow{2}{*}{$\begin{array}{c}457 \\
(18.33)\end{array}$} & 1221 & 24.73 \\
\hline & Male & 29 & 126 & 155 & & 1271 & 12.19 \\
\hline \multirow{2}{*}{$50-54$} & Female & 47 & 260 & 307 & \multirow{2}{*}{$\begin{array}{c}492 \\
(26.24) \\
\end{array}$} & 880 & 34.88 \\
\hline & Male & 27 & 158 & 185 & & 995 & 18.59 \\
\hline \multirow{2}{*}{$55-59$} & Female & 25 & 202 & 227 & \multirow{2}{*}{$\begin{array}{c}355 \\
(21.24)\end{array}$} & 838 & 27.08 \\
\hline & Male & 18 & 110 & 128 & & 817 & 15.66 \\
\hline Higher & Female & 70 & 391 & 461 & 818 & 2078 & 22.18 \\
\hline than 60 & Male & 65 & 292 & 357 & $(20.41)$ & 1928 & 18.51 \\
\hline Total & & 1579 & 9207 & 10786 & 10786 & 46791 & 23.05 \\
\hline
\end{tabular}


As it can be seen, $42.4 \%$ of the active lesions were secretory and $57.6 \%$ were non-secretory. The independency between the two attributes o interest, i.e. gender, and type of lesion, is shown by Fishers exact test (0.218). The results of the study concerning the number of leishmaniasis lesions (active lesions and scars) indicated that most patients had only one scar (Table 4).

Table 4: The frequency of active lesions and scars among the patients

\begin{tabular}{ccccc}
\hline \multirow{2}{*}{$\begin{array}{c}\text { Frequency of active } \\
\text { lesions and scars }\end{array}$} & \multicolumn{2}{c}{ Lesion } & \multicolumn{2}{c}{ Scar } \\
\cline { 2 - 5 } & $\begin{array}{c}\text { Female } \\
\text { Number (\%) }\end{array}$ & $\begin{array}{c}\text { Male } \\
\text { Number (\%) }\end{array}$ & $\begin{array}{c}\text { Female } \\
\text { Number (\%) }\end{array}$ & $\begin{array}{c}\text { Male } \\
\text { Number (\%) }\end{array}$ \\
\hline $\mathbf{1}$ & $360(40.6)$ & $295(42.6)$ & $2280(45.5)$ & $1953(46.5)$ \\
\hline $\mathbf{2}$ & $222(25.1)$ & $187(27)$ & $1332(26.6)$ & $1160(27.6)$ \\
\hline 3 and more & $304(34.3)$ & $210(30.3)$ & $1396(27.9)$ & $1077(25.7)$ \\
\hline Total & $886(100)$ & $692(100)$ & $5008(100)$ & $4190(100)$ \\
\hline
\end{tabular}

The findings showed that $18.4 \%$ of the families did not have bed nets and $6.6 \%$ of those who had bed nets did not use them. It was also found that $92.8 \%$ of the patients used bed nets.

In addition, the means and standard deviations for the time of installation, packing, and using bed nets were $20.73 \pm 1.284,7.22 \pm 0.851$, and $13.52 \pm 1.403$ hours, respectively. The results of KolmogorovSmirnov test showed that the data are not normally distributed.

The results of t-test indicated that there was no statistically significant relationship between the average time of installing bed nets by families with new cases of leishmaniasis ( $20.81 \pm 1.262$ hours) and the families without new cases $(20.79 \pm 1.315$ hours) ( $\mathrm{t}=0.373, \mathrm{df}=1135.321, \mathrm{p}=0.709)$. In contrast, there was a significant relationship between the average time of packing the bed nets by families with new cases of the disease $(7.30 \pm 0.89$ hours) compared to the families without new cases (7.19 \pm 0.83 hours) ( $\mathrm{t}=3.451, \mathrm{df}=1088.172, \mathrm{p}=0.001)$. Besides, no significant relationship was found between the average durations of using bed nets by families with new cases of leishmaniasis (13.51 \pm 1.39 hours) compared to the families without new cases ( $13.60 \pm 1.42$ hours) $(t=-1.826, d f=8921$, $\mathrm{p}=0.068)$.

The results of the Chi-square test indicated a statistically significant relationship between using bed nets and developing leishmaniasis $(X=23.932$, $\mathrm{df}=1, \mathrm{p}=0.001$ ).

The Pearson test demonstrated a statistically significant relationship between age and the number of leishmaniasis-induced scars $(r=0.146$, $\mathrm{p}=0.001)$. There was also a significant relationship between age and active lesions $(r=0.171, p=0.001)$. The results of $\mathrm{t}$-test showed that there was a statistically significant difference between the mean age of the people with secretive lesions (27.51 $\pm 22.975)$ and that of the people with non-secretive lesions $(24.74 \pm 20.344)$. The results of the Fisher's exact test showed that there was no significant difference between the gender and type of lesion in terms of secretion (Fisher $=0.06$ ). Besides, no significant relationship was found between gender and the number of active lesions ( $t=1.620$, $\mathrm{df}=3785.200, p=0.105)$. Furthermore, the results of the chi-square test showed no statistically significant relationship between gender and secretive active lesions (Chi 0.327, $\mathrm{df}=1, \mathrm{p}=0.568$ ). Of 10786 people with leishmaniasis, a total of 68 patients (42.65\% males and $57.35 \%$ females) developed the disease for the second time. This study showed that the risk of the disease for recurrence in the region in question was $0.63 \%$.

\section{Discussion}

The World Health Organization (WHO) has advocated and recommended studies on various aspects of leishmaniasis (31). The stigmas left by cutaneous leishmaniasis can cause many mental problems for the patients. For instance, Afghan mothers with cutaneous leishmaniasis scar are forbidden to touch their children, and young women with cutaneous leishmaniasis scars are not allowed to get married. In Colombia, cutaneous leishmaniasis scars are used as a reason for men to abandon their wives (32). Given the lack of research on the prevalence of cutaneous leishmaniasis in the world, this cross-sectional study investigated the lifetime prevalence of cutaneous leishmaniasis scars in the city of Kherameh in 2015. The main findings of this study showed that the overall prevalence of the infection was $31.49 \%$, with a higher rate among the females than the males. However, other studies conducted in Iran reported higher prevalence rates among men than women $(33,11)$. Similarly, Yazdanpanah et al. found that the prevalence of cutaneous leishmaniasis was twice as much among men than women (22). The prevalence of the disease was higher among men in the studies conducted by Nilforoushzadeh et al., in Isfahan, Reithinger et al. in Afghanistan, Soares et al in Amazon Center [34- 
36]. Women's skin is more tender and sensitive than men's $(37,38)$. The higher prevalence of the disease among females compared to males can be because of their more sensitive skin, which may increase the probability of bites and higher prevalence of the disease.

The highest prevalence of the disease was found in the participants in age group below 10 years old. In the present study, $3.63 \%$ of the people had an active lesion and the highest frequency of the infection $(21.91 \%)$ was found in the age group $0-4$. This finding is consistent with the results of a study by Khajedaluee et al. in Khorasan (39). In another study by Doroodgar et al., the highest prevalence of the infection was found in the age group 20-29 years old in Kashan (40). Findings of our study revealed the high endemicity of the disease in Kherameh.

The findings of the study showed that the patients often had one lesion that matched the epidemiological condition of rural cutaneous leishmaniasis. Given the observation made by Saberi et al. (41) who indicated that hunted rodents in the city of Kherameh were all Tatera indica and the only parasite found was L-Major, it might be implied that cutaneous leishmaniasis in the region of the study was the rural type of the disease. The present study found a weak, positive and significant relationship between age, the number of scars, and the number of active lesions caused by leishmaniasis. This was consistent with the results of a study by Mesgarian et al. (14) who suggested that the number of lesions caused by cutaneous leishmaniasis would increase with age. The results also showed that active lesions got secretive at higher ages. According to the investigations and also based on the fact that self-treatment was common in the city of Kherameh especially among older people; the number of secretive lesions could increase.

There was a statistically significant relationship between gender and the number of leishmaniasisinduced scars. In other words, the number of lesions was higher in women than men, and the reason might be the fact that women's skin was more sensitive than that of men. However, no statistically significant relationship was found between gender and the number of active lesions, as indicated by the previous research (42). The results also showed that there was no significant relationship between gender and secretion of active lesions. In other words, these two characteristics were independent of each other.

The findings of our study indicated that $25 \%$ of the families under study did not use bed nets and it might be due to their low income. The study conducted by Abazid et al. in Aleppo (Syria) showed that although it was commonly believed that using bed nets was the best preventive way, the families' behaviors in terms of using personal protective equipment such as bed nets, insecticides, and window screens was still low (43). In the studies conducted by Heshmati et al. [44] in Yazd and Vahhabi et al. (45) in Dehloran, the rate of using personal protective equipment by families was low. The finding of the present study also showed that $92.8 \%$ of the patients with active lesions used bed nets. The study carried out by Ali et al. (46) revealed that only $25.20 \%$ of the patients used bed nets. The effectiveness of using bed nets in preventing leishmaniasis depended on various factors including treatment with insecticide, the shape and size of the nets, and whether the nets were torn or not (35). Faraj et al. and Jalouk et al. suggested that using mosquito nets covered with insecticides did not have a high efficiency and significant effect on decreasing leishmaniasis. However, Hubertus et al. stated that preventing the disease through the use of mosquito nets not covered with insecticides was often impossible (4749). Given the fact that most patients were using bed nets, and the families using bed nets were only 1.41 times less likely to develop leishmaniasis compared to those who did not use bed nets, it could be said that using bed nets had little effects on preventing leishmaniasis. However, further research is needed to test the effect of using bed nets in preventing leishmaniasis.

The present study showed that there was no significant relationship between installing bed nets and developing leishmaniasis. The results of a study by Mohaghegh et al. showed that phlebotomine were active from 7 P.M. to 6 A.M. (50). The families with lower frequency of using bed nets from 7 P.M to 9 P.M developed active phlebotomine. It was also found out that the time of packing bed nets had an impact on developing leishmaniasis. In other words, packing bed nets late would have an impact on developing leishmaniasis, as this would decrease of insecticide effects and the lower resistance of the mosquito nets due to the sunshine. The findings of the study showed that the duration of using bed nets was not effective in developing leishmaniasis. In other words, leaving bed nets installed in unnecessary hours did not affect the control of the disease. In addition, leaving the bed nets installed for a long time might cause them to get torn and their protective effect might decrease.

The present study indicated that the risk of developing leishmaniasis for the second time was $0.63 \%$ in the city of Kherameh. The study carried out by Jaffari et al. in Isfahan showed a recurrence rate of $6.8 \%$ (17). It is worth mentioning that recall bias might exist in this regard. That is to say, it may 
be possible if the people with leishmaniasis had been slightly wrong when telling the first year of developing the disease. It is recommended that such similar studies be replicated in cities with a high prevalence of cutaneous leishmaniasis and compare their findings with the results of this study.

\section{Conclusion}

Cutaneous leishmaniasis has been increasing in recent years and this can be due to climate change or implemented controlling actions (education, waste of rats and distribution of bed nets) which might be either done incorrectly or they did not have a significant role in decreasing the rate of the disease. Hence, accurate and comprehensive studies have to be done to investigate each possible reason.

\section{Acknowledgement}

The authors would like to thank the health worker providers of the Kherameh Healthcare Network who helped us with this research.

\section{Conflict of interest: None declared.}

\section{References}

1. Vazirianzadeh B, Hoseini SA, Pour Rezaee S, Gardani H, Amraee K. Prevalence of cutaneous leishmaniasis in Ramshir, Iran; an epidemiological study. Quarterly of International Archives of Health Sciences 2014;1(1):37-41.

2. Miura R, Kooriyama T, Yoneda M, Takenaka A, Doki M, Goto $Y$, et al. Efficacy of recombinant canine distemper virus expressing leishmania antigen against leishmania challenge in dogs. PLoS Negl Trop Dis 2015; 9(7):e0003914.

3. Maroli M, Feliciangeli MD, Bichaud L, Charrel RN, Gradoni L. Phlebotomine sandflies and the spreading of leishmaniases and other diseases of public health concern. . Med Vet Entomol 2013; 27(2):123-47.

4. Savoia D. Recent updates and perspectives on leishmaniasis. J Infect Dev Ctries 2015; 9(6):588-96.

5. Achtman JC, Ellis DL, Saylors B, Boh EE. Cutaneous leishmaniasis caused by Leishmania (Viannia) panamensis in 2 travelers. JAAD Case Rep 2016; 2(2):95-7.

6. Entezari M, Eskandari F. Relationship between climatic factors and the prevalence of cutaneous leishmaniasis in Larestan city. Journal of Military Medicine 2014; 16(2):99-104.

7. Olalla HR, Velez LN, Kato $H$, Hashiguchi $K$, Caceres AG, Gomez EA, et al. An analysis of reported cases of leishmaniasis in the southern Ecuadorian Amazon region, 1986-2012. Acta Trop 2015; 146:119-26.

8. Oré M, Sáenz E, Cabrera R, Sanchez JF, De Los Santos MB, Lucas CM, et al. Outbreak of cutaneous leishmaniasis in Peruvian military personnel undertaking training activities in the Amazon basin, 2010. Am J Trop Med Hyg 2015; 93(2):340-6.

9. Mondragon-Shem K, Acosta-Serrano A. Cutaneous leishmaniasis: The truth about the 'Flesh-Eating Disease' in Syria. Trends Parasitol 2016; 32(6):432-5.

10. Alvar J, Vélez ID, Bern C, Herrero M, Desjeux $P$, Cano J, et al. Leishmaniasis worldwide and global estimates of its incidence. PLoS One 2012; 7(5):e35671.

11. Khosravani M, Nasiri Z, Keshavarz D, RafatPanah A. Epidemiological trend of cutaneous leishmaniasis in two endemic focus of disease, south of Iran. J Parasit Dis 2016; 40(4):1609-13.

12. Ono M, Takahashi K, Taira $K$, Uezato $H$, Takamura S, Izaki S. Cutaneous leishmaniasis in a Japanese returnee from West Africa successfully treated with liposomal amphotericin B. J Dermatol 2011; 38(11):1062-5.

13. Haouas N. Estimations of cutaneous leishmaniasis burden: a constant challenge. Lancet Infect Dis 2016; 16(5):515-6.

14. Mesgarian F, Rahbarian N, Mahmoudi Rad M, Hajaran H, Shahbaz F, Mesgarian Z, et al. Identification of leishmania species isolated from human cutaneous leishmaniasis in Gonbad-eQabus city using a PCR method during 20062007. Tehran University Medical Journal 2010; 68(4):250-6.

15. Bennis I, De Brouwere V, Ameur B, El Idrissi Laamrani A, Chichaoui S, Hamid S, et al. Control of cutaneous leishmaniasis caused by Leishmania major in south-eastern Morocco. Trop Med Int Health 2015; 20(10):1297-305.

16. Saatchi $M$, Salehiniya $H$, Khazaei $S$, Mohammadian M, Mohammadian-Hafshejani A. Cutaneous leishmaniasis in Iran: Demographic description and therapeutic outcomes. Journal of Dermatology and Cosmetic 2015; 6(2):108-18.

17. Jaffary F, Nilforoushzadeh MA, Abdellahi L, Mortazaei S. Cutaneous leishmaniasis reinfection: Skin Disease and Leishmaniasis Research Center, Isfahan, Iran. Journal of Isfahan Medical School 2015; 33(341):1029-36.

18. Mitropoulos P, Konidas P, Durkin-Konidas M. New World cutaneous leishmaniasis: updated review of current and future diagnosis and treatment. J Am Acad Dermatol 2010; 63(2):30922.

19. Nejad Nayrisi H, Alhani F, Anoosheh M, Faghihzadeh $\mathrm{S}$. The effect of designed home visit program on promoting cutaneous leishmaniasis preventive behaviors. Iran Journal of Nursing 2007; 20(49):73-100.

20. Zahirnia A, Moradi A, Norozi NA, Bathaii SJN, Erfani $H$, Moradi A. Epidemiology survey of cutaneous leishmaniasis in Hamadan province (2002-2007). Avicenna Journal of Clinical Medicine 2009; 16(1):43-7.

21. Sarkari B, Qasem A, Shafaf MR. Knowledge, attitude, and practices related to cutaneous 
leishmaniasis in an endemic focus of cutaneous leishmaniasis, Southern Iran. Asian Pac J Trop Biomed 2014; 4(7):566-9.

22. Yazdanpanah $H$, Baratiyan $A$, Karimi $S$. Investigation of the relationship of the climatic factors and prevalence of cutaneous in Ghasr Shirin City. Journal of Spatial Planning 2013; 3(3):69-86.

23. Jarahi L, Tayarani Bathaee A, Erfanian MR. A study on the effect of physical environment conditions on the prevalence of cutaneous leishmaniasis in leishmania hyperendemic area in Mashhad. Journal of Research in Environmental Health 2015; 1(3):228-33.

24. Saberi S, Zamani A, Moatamedi N, Nilforoushzadeh MA, Jaffary F, Rahimi E, et al. The knowledge, attitude and prevention practices of students regarding cutaneous leishmaniasis in the hyperendemic region of the Shahid Babaie Airbase. Vector Borne Zoonotic Dis 2012; 12(4):306-9.

25. Reithinger R, Dujardin JC, Louzir H, Pirmez C, Alexander B, Brooker S. Cutaneous leishmaniasis. Lancet Infect Dis 2007; 7(9):58196.

26. Khazaei S, Mohammadian Hafshejani A, Saatchi M, Salehiniya H, Nematollahi Sh. Epidemiological aspects of cutaneous leishmaniasis in Iran. Arch Clin Infect Dis 2015; 10(3):e28511.

27. Inci R, Ozturk P, Mulayim MK, Ozturk K, Alatas $E T$, Inci MF. Effect of the syrian civil war on prevalence of cutaneous leishmaniasis in southeastern Anatolia, Turkey. Med Sci Monit 2015; $21: 2100-4$.

28. Khan I, Hussain M, Ul Akbar N, Ahmad H, Ahmad W, Waqar $M$, et al. Prevalence of cutaneous leishmaniasis in Surgul village of district Kohat, Khayber Pakhtunkhwa. International Journal of Advancements in Research \& Technology 2013; 2(12):141-7.

29. Eilami O, Khalili RS. Frequency of cutaneous leishmaniasis among patients referred to the Center for Disease Control in Kuhgilooyeh and Boyerahmad province 2009-2013. International Journal of Infectious Diseases 2016; 45(Supplement 1):222.

30. Aflatotounian MR, Sharifi I. Prevalence rete of cutaneous leishmaniasis in Bam district during 20 years (1988-2007). Journal of Kerman University of Medical Sciences 2010; 17(4):297306.

31. Nejati J, Mojadam M, Hanafi Bojd AA, Keyhani A, Habibi Nodeh F. An epidemiological study of cutaneous leishmaniasis in Andimeshk (20052010). Journal of Ilam University of Medical Sciences 2014; 21(7):94-101.

32. Alvar J, Yactayo S, Bern C. Leishmaniasis and poverty. Trends Parasitol 2006; 22(12):552-7.

33. Poorsmaelian S, Mirzaei M, Sharifi I, Zarean M. The prevalence of cutaneous leishmaniasis in the city and suburb of Mohammadabad, Jiroft district and identification of parasite species by
Nested-PCR, 2008. Journal of Kerman University of Medical Sciences 2011; 18(3):21827.

34. Nilforoushzadeh MA, Shirani-Bidabadi L, Hosseini SM, Fadaei-Nobari R, Jaffary F. The epidemiology of cutaneous leishmaniasis in Isfahan province, Iran, during 2001-2011. Journal of Isfahan Medical School 2015; 32(315):2241-51.

35. Reithinger R, Mohsen M, Leslie T. Risk factors for anthroponotic cutaneous Leishmaniasis at the household level in Kabul, Afghanistan. PLoS Negl Trop Dis 2010; 4(3):e639.

36. Soares L, Abad-Franch F, Ferraz G. Epidemiology of cutaneous leishmaniasis in central Amazonia: a comparison of sex-biased incidence among rural settlers and field biologists. Trop Med Int Health 2014; 19(8):98895.

37. Yoon-Soo B, Boer-Kimball A, Alora-Palli M. Gender differences in perceptions of aging. J Am Acad Dermatol 2009; 60(3):AB24.

38. Sparavigna A, Setaro M, Di Pietro A. Heathy skin 2005": results of an Italian study on healthy population with particular regard to the aging phenomenon. Journal of Plastic Dermatology 2006; 2:23-9.

39. Khajedaluee M, Yazdanpanah MJ, Seyed Nozadi SM, Fata A, Juya MR, Masoudi MH, et al. Epidemiology of cutaneous leishmaniasis in Razavi Khorasan in 2011. Medical Journal of Mashhad University of Medical Sciences 2014; 57(4):647-54.

40. Doroodgar A, Mahbobi S, Nemetian M, Sayyah M, Doroodgar M. An epidemiological study of cutaneous leishmaniasis in Kashan (2007-2008). Journal of Semnan University of Medical Sciences 2009; 10(3):177-84.

41. Saberi S, Hejazi SH, Jafari R, Bahadoran M, Akbari M, Soleymanifard S, et al. The cutaneous leishmaniasis reservoirs in northern Baraan region of Isfahan, Iran. Journal of Isfahan Medical School 2013; 31(253):1497-507.

42. Babaei GhR, Shayan A. An epidemiological study of cutaneous leishmaniasis and the investigation of scar with emphesis on seasons, age and sex group in paalam, south of Lorestan province. Armaghane danesh Journal 2003; 8(29):51-8.

43. Abazid N, Jones C, Davies CR. Knowledge, attitudes and practices about leishmaniasis among cutaneous leishmaniasis patients in Aleppo, Syrian Arab Republic. East Mediterr Health J 2012; 18(1):7-14.

44. Heshmati H, Charkazi A, Hazavehei SMM, Rahaei Z, Dehnadi A. Factors related to cutaneous leishmaniasis preventive behaviors on the basis of BASNEF Model in residents of endemic areas in Yazd, Iran. Journal of Researches in Health System 2011; 7(6):926-34.

45. Vahabi A, Rassi Y, Oshaghi MA, Vahabi B, Rafizadeh S, Sayyad S. First survey on knowledge, attitude and practice about 
cutaneous leishmaniasis among dwellers of Musian district, Dehloran county, southwestern of Iran. Life Sci J 2013; 10(12 SPL.ISS):864-8.

46. Ali A, Ur Rehman T, Akhtar Qureshi A, Ur Rahman $\mathrm{H}$. New endemic focus of cutaneous leishmaniasis in Pakistan and future epidemics threats. Asian Pac J Trop Dis 2016; 6(2):155-9.

47. Faraj C, Yukich J, Adlaoui EB, Wahabi R, Mnzava AP, Kaddaf M, et al. Effectiveness and cost of insecticide-treated bed nets and indoor residual spraying for the control of cutaneous leishmaniasis: A cluster-randomized control trial in Morocco Am J Trop Med Hyg 2016; 4(3):67985.
48. Jalouk L, Al Ahmed M, Gradoni L, Maroli M. Insecticide-treated bednets to prevent anthroponotic cutaneous leishmaniasis in Aleppo Governorate, Syria: results from two trials. Trans R Soc Trop Med Hyg 2007; 101(4):360-7.

49. Neuber H. Leishmaniasis. J Dtsch Dermatol Ges 2008; 6(9):754-65.

50. Mohaghegh A. survey of epidemiological parametric of cutaneous leishmaniasis, determination of dominant species and nocturnal activity of sand flies in sultanabad area of shiraz as a new foci during 2004-2005. [PhD thesis]. Shiraz: Shiraz University of Medical Sciences; 2005. 